\title{
Identification of Noncompetitive Protein-Ligand Interactions for Structural Optimization
}

\section{Supporting Information}

Andreas Tosstorff, ${ }^{* *}$ Jason Cole, ${ }^{*}$ Robin Taylor, ${ }^{*}$ Seth F. Harris, ${ }^{\perp}$ and Bernd Kuhn ${ }^{\dagger}$

${ }^{\dagger}$ Roche Pharma Research and Early Development, Roche Innovation Center Basel, F. Hoffmann-La Roche Ltd., Grenzacherstrasse 124, 4070 Basel, Switzerland

†Cambridge Crystallographic Data Centre, 12 Union Road, Cambridge CB2 1EZ, U.K.

${ }^{\perp}$ Structural Biology, Genentech, Inc., 1 DNA Way, South San Francisco, California 94080, United States 
Table S1: Occurrences of tyrosine and serine/threonine bound O_mix atoms as a function of the protein contact angle. For the angle range $100^{\circ}-120^{\circ}$, a large majority of contacts can be attributed to tyrosine bound O_mix.

\begin{tabular}{c|c|c|c|c|c|c}
$\begin{array}{c}\text { O_mix protein } \\
\text { contact angle } \\
\text { range }\end{array}$ & $\mathbf{0}^{\circ}-\mathbf{2 0}^{\circ}$ & $\mathbf{2 0}^{\circ}-\mathbf{4 0}^{\circ}$ & $\mathbf{4 0}^{\circ}-\mathbf{6 0}^{\circ}$ & $\mathbf{6 0}^{\circ}-\mathbf{8 0}^{\circ}$ & $\mathbf{8 0}^{\circ}-\mathbf{1 0 0}^{\circ}$ & $\mathbf{1 0 0}^{\circ} \mathbf{- 1 2 0}^{\circ}$ \\
\hline O_mix_Tyr & 6 & 11 & 25 & 52 & 28 & 29 \\
O_mix_Ser/Thr & 9 & 22 & 25 & 40 & 23 & 13
\end{tabular}

Figure S1: Relationship between $\mathrm{C}-\mathrm{Cl}$...carbon_O_mix and $\mathrm{C}-\mathrm{O} \_$mix...Cl contact angles. Angle definitions are as defined in Figure 2. Entries with halogen- $\pi$ interaction geometry are circled.

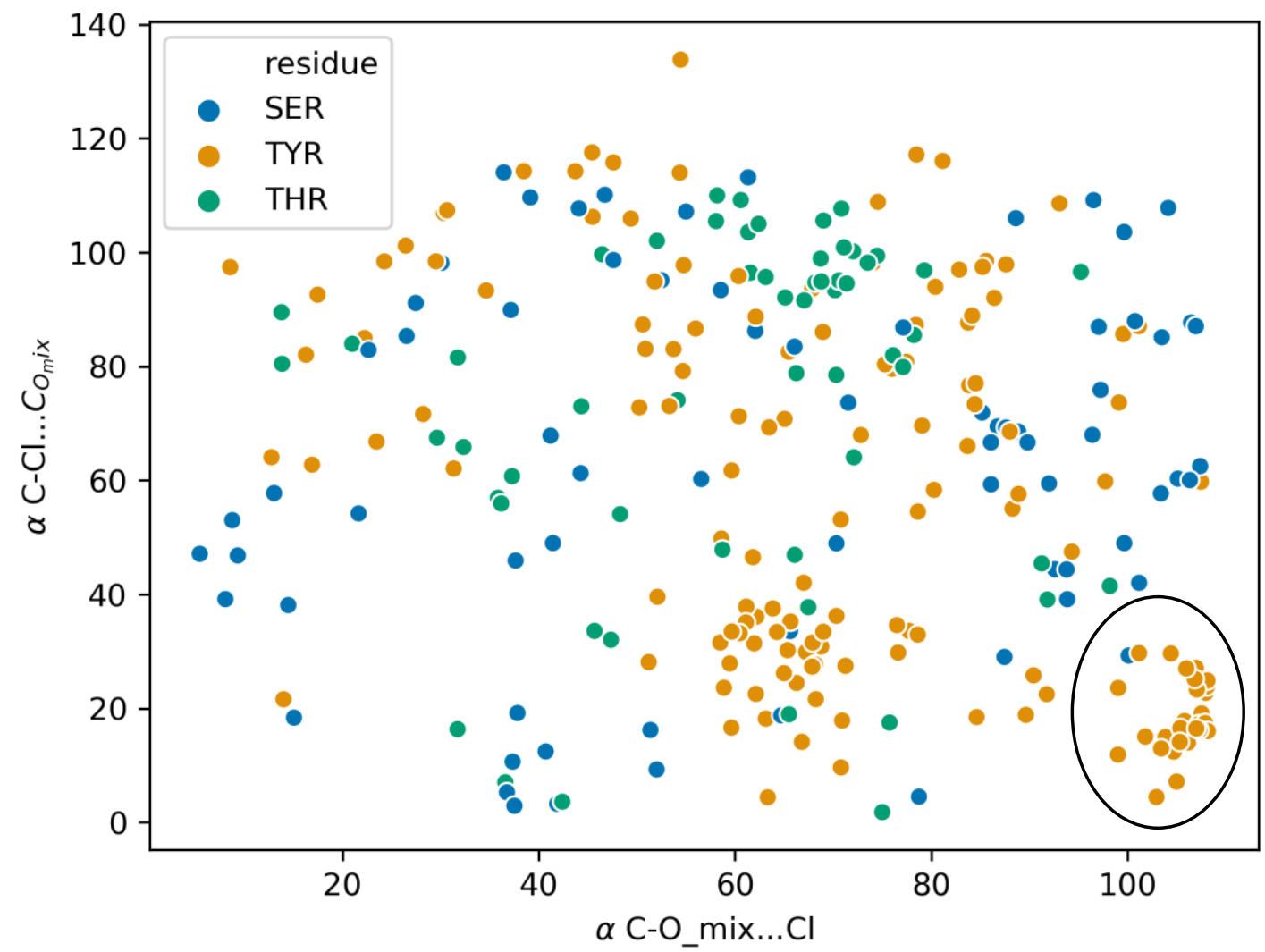

Figure S2: C1...O_mix contact with protein contact angle alpha $=108^{\circ}$

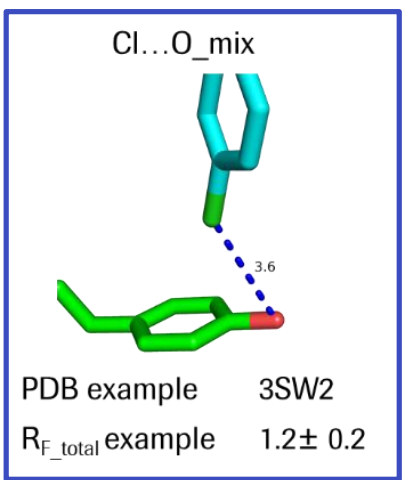


Table S2: Median $\mathrm{R}_{\mathrm{F}_{-} \text {total }}$ values for halogen contacts with C_ali_apol in the PDB

\begin{tabular}{c|c|c|c|c|c|c}
\multirow{2}{*}{ SMARTS } & \multicolumn{7}{|c}{ C_ali_apol } \\
\cline { 2 - 7 } & $\begin{array}{c}\mathbf{0}^{\circ} \leq \\
\boldsymbol{\alpha} \text { ligand } \\
\mathbf{2 0}^{\circ}\end{array}$ & $\begin{array}{c}\mathbf{2 0}^{\circ} \leq \\
\boldsymbol{\alpha} \text { lligand } \\
\mathbf{4 0}^{\circ}\end{array}$ & $\begin{array}{c}\mathbf{4 0}^{\circ} \leq \\
\boldsymbol{\alpha} \text { ligand } \\
\mathbf{6 0}^{\circ}\end{array}$ & $\begin{array}{c}\mathbf{6 0}^{\circ} \leq \\
\boldsymbol{\alpha} \text { ligand } \\
\mathbf{8 0}^{\circ}\end{array}$ & $\begin{array}{c}\mathbf{8 0}^{\circ} \leq \\
\boldsymbol{\alpha} \text { ligand } \\
\mathbf{1 0 0}^{\circ}\end{array}$ & $\begin{array}{c}\mathbf{1 0 0}^{\circ} \leq \\
\boldsymbol{\alpha} \text { ligand } \\
\mathbf{1 2 0}^{\circ}\end{array}$ \\
\hline$[\mathbf{c}][\mathrm{Br}]$ & 0.93 & 0.93 & 1.01 & 1.06 & 1.08 & 1.09 \\
{$[\mathbf{c}][\mathbf{C l}]$} & 0.96 & 1.01 & 1.06 & 1.08 & 1.13 & 1.16 \\
{$[\mathbf{c}][\mathbf{F}]$} & 1.17 & 1.15 & 1.16 & 1.18 & 1.17 & 1.18 \\
{$[\mathbf{c}][\mathbf{I}]$} & 0.90 & 0.98 & 1.04 & 0.99 & 1.07 & 1.11
\end{tabular}

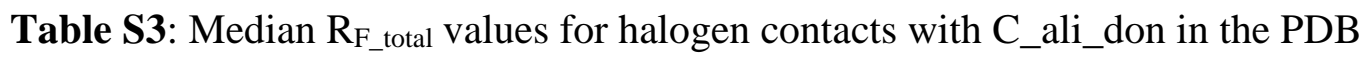

\begin{tabular}{|c|c|c|c|c|c|c|}
\hline \multirow[b]{2}{*}{ SMARTS } & \multicolumn{6}{|c|}{ C_ali_don } \\
\hline & $\begin{array}{c}0^{\circ} \leq \\
\alpha_{-} \text {ligand } \\
20^{\circ}\end{array}$ & $\begin{array}{c}20^{\circ} \leq \\
\alpha_{-} \text {ligand } \\
40^{\circ}\end{array}$ & $\underset{\text { a_ligand }}{40^{\circ} \leq}<$ & $\begin{array}{c}60^{\circ} \leq \\
\underset{\text { alligand }}{80^{\circ}}<\end{array}$ & $\begin{array}{c}80^{\circ} \leq \\
\alpha \_ \text {ligand }< \\
100^{\circ}\end{array}$ & $\begin{array}{c}100^{\circ} \leq \\
\alpha \_ \text {ligand }< \\
120^{\circ}\end{array}$ \\
\hline$[\mathrm{c}][\mathrm{Br}]$ & 1.00 & 1.04 & 1.09 & 1.10 & 1.02 & 0.87 \\
\hline$[\mathrm{c}][\mathrm{Cl}]$ & 0.91 & 1.00 & 1.14 & 1.17 & 1.12 & 0.93 \\
\hline$[\mathbf{c}][\mathbf{F}]$ & 1.28 & 1.27 & 1.23 & 1.12 & 1.06 & 1.18 \\
\hline$[\mathrm{c}][\mathbf{I}]$ & 1.04 & 1.04 & 1.05 & 1.18 & 1.12 & \\
\hline
\end{tabular}


Figure S3: Heat maps for fluorine bound to aromatic carbon

\section{[c]-[F]}

Expected $\geq 10$ mode: protein smarts_index: 1

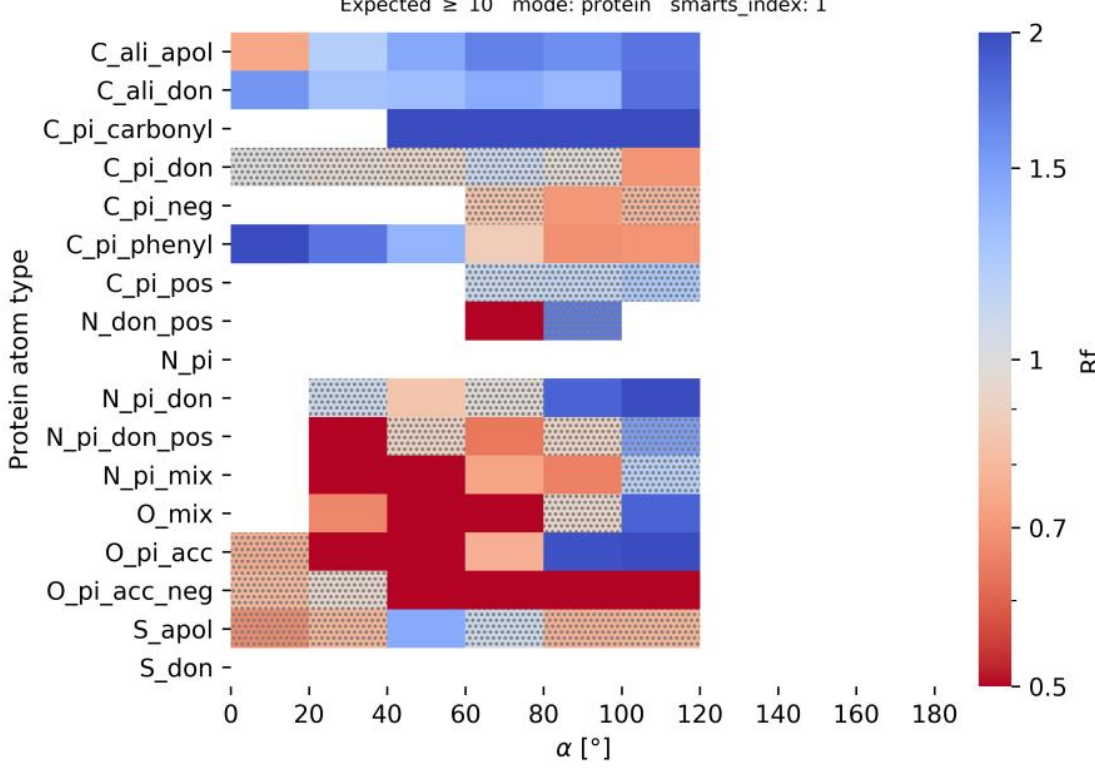

\section{[c]-[F]}

Expected $\geq 10$ mode: protein smarts_index: 1

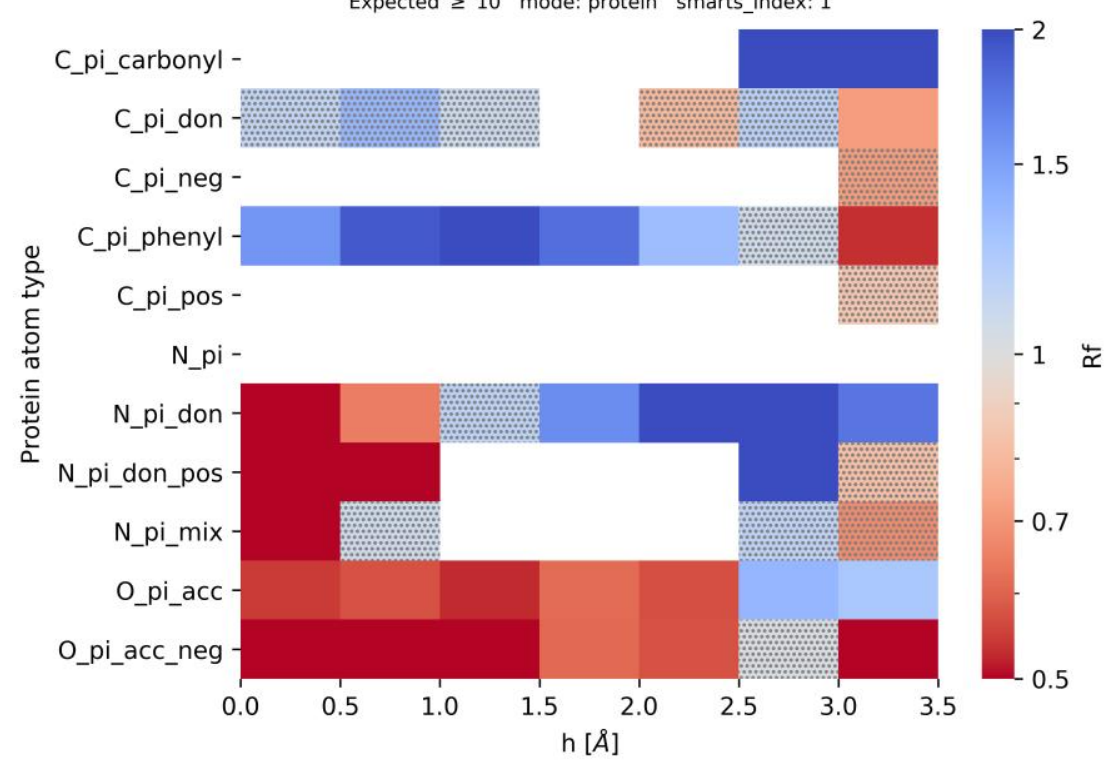

\section{[c]-[F]}

Expected $\geq 10$ mode: ligand smarts_index: 1

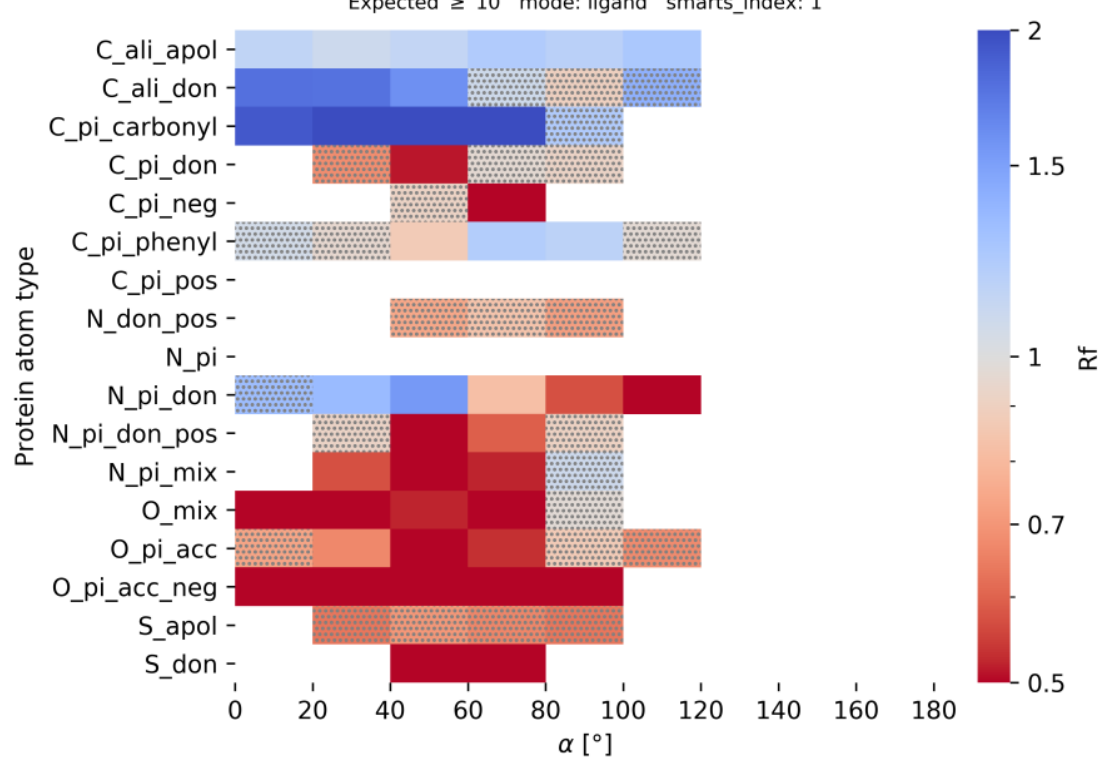


Figure S4: Heat maps for bromine bound to aromatic carbon

\section{[c]-[Br]}

Expected $\geq 10$ mode: protein smarts_index: 1

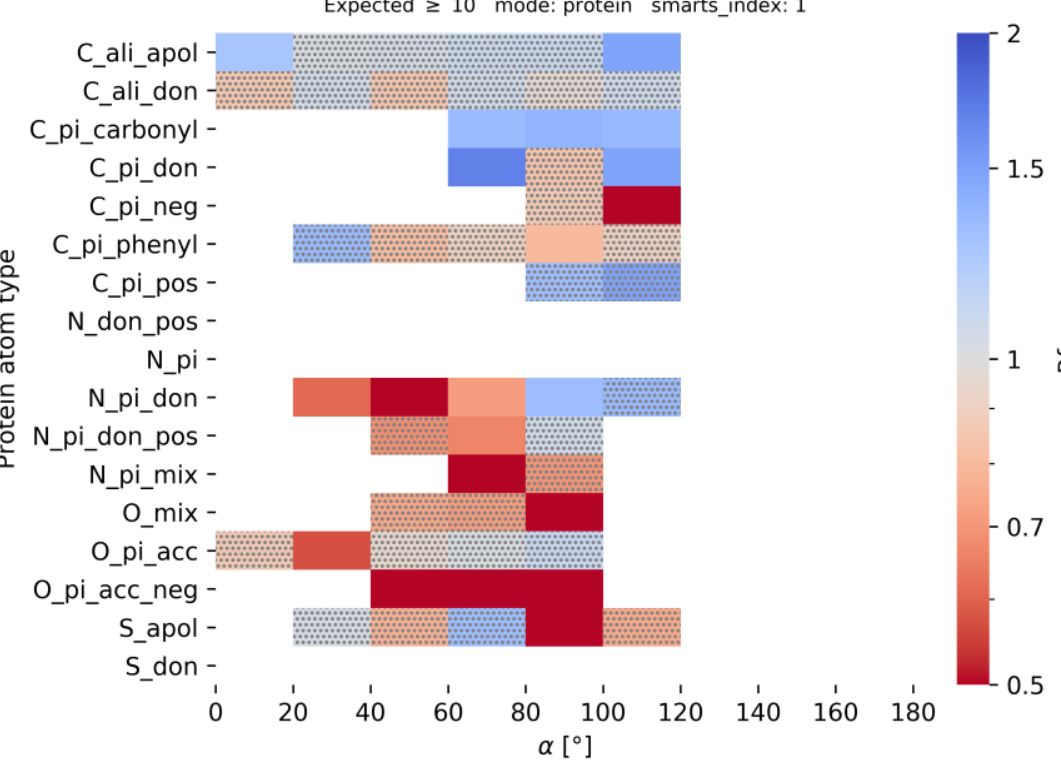

\section{[c]-[Br]}

Expected $\geq 10$ mode: protein smarts_index: 1

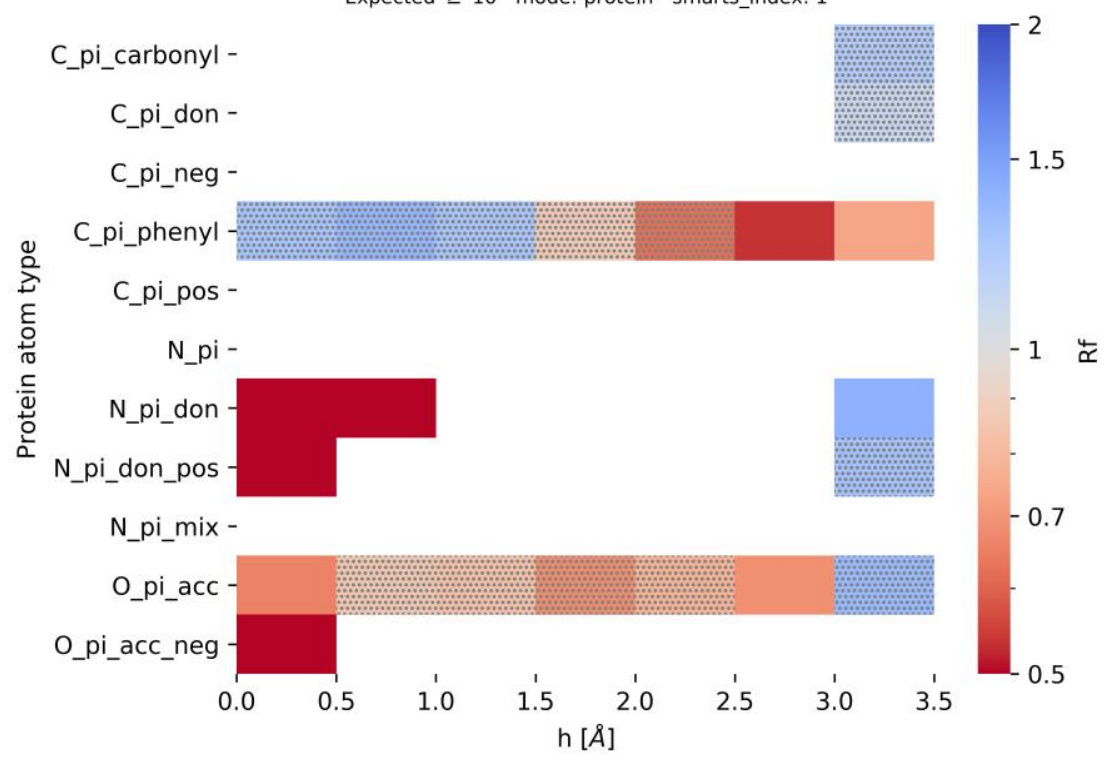

\section{[c]-[Br]}

Expected $\geq 10$ mode: ligand smarts_index: 1
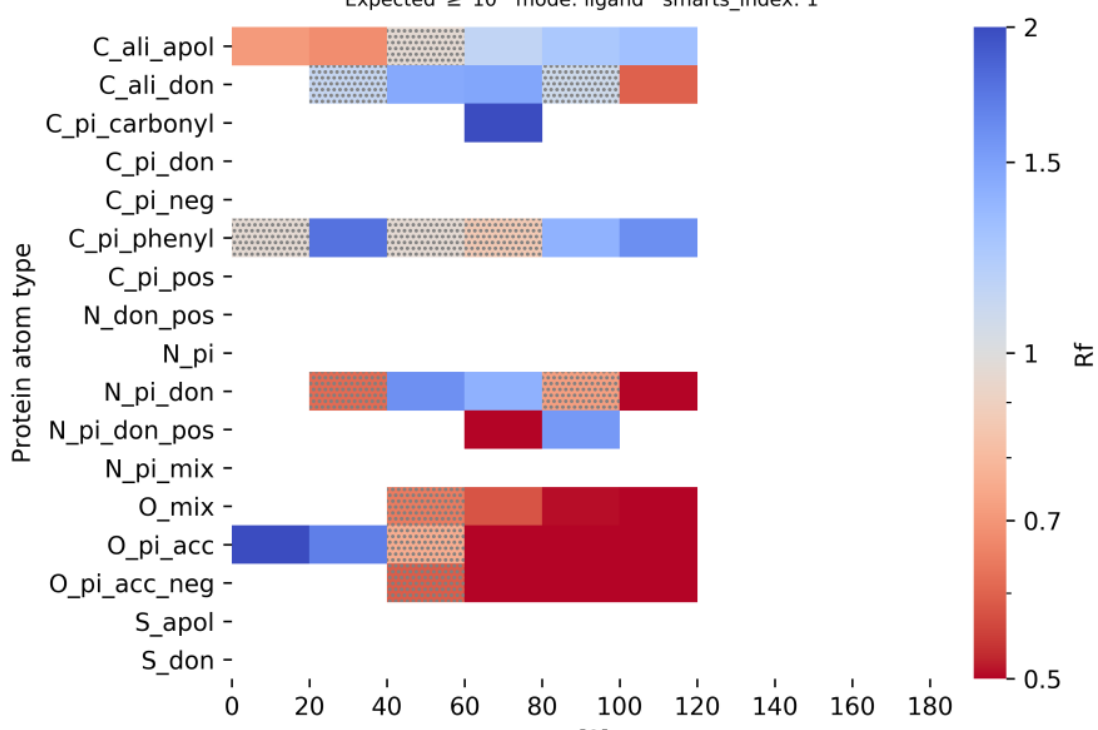
$\alpha\left[^{\circ}\right]$ 
Figure S5: Heat maps for iodine bound to aromatic carbon

\section{[c]-[I]}

Expected $\geq 10$ mode: protein smarts index:

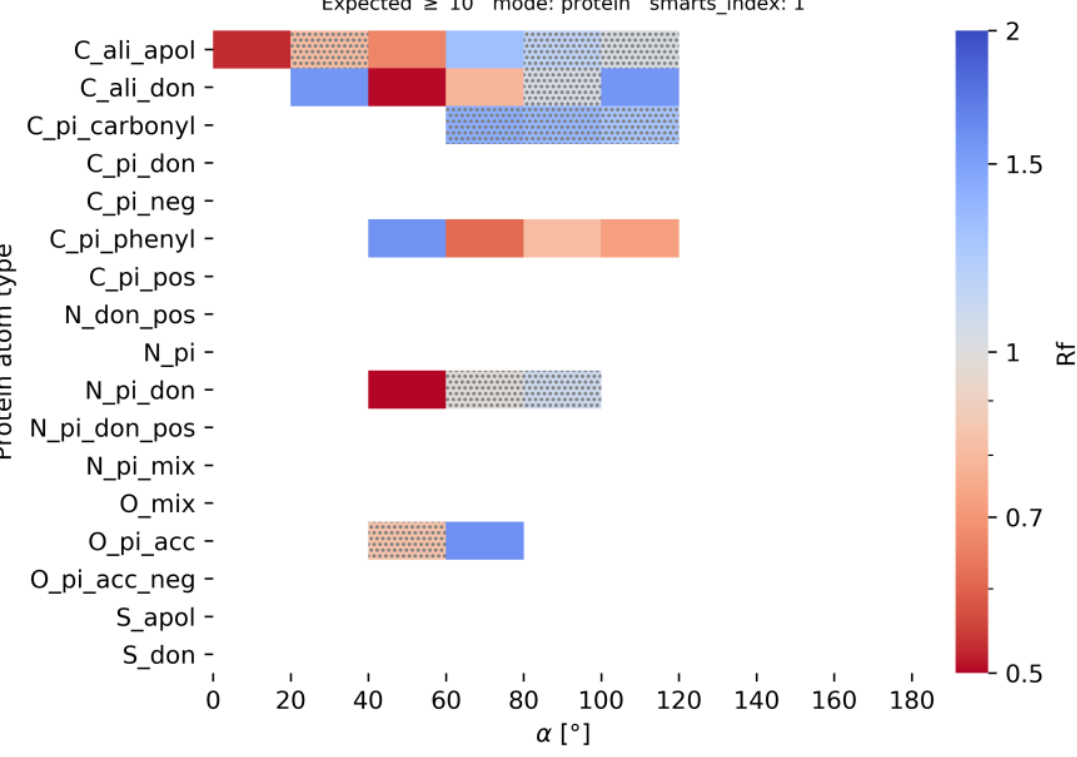

\section{[c]-[I]}

Expected $\geq 10$ mode: protein smarts_index: 1

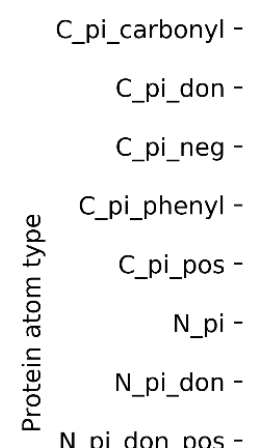

N_pi_don_pos -

N_pi_mix -

O_pi_acc -

O_pi_acc_neg -
0.0

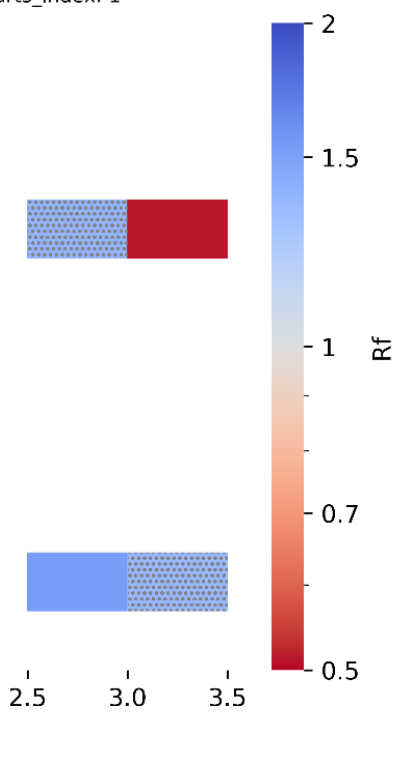

\section{[c]-[I]}

Expected $\geq 10$ mode: ligand smarts_index: 1

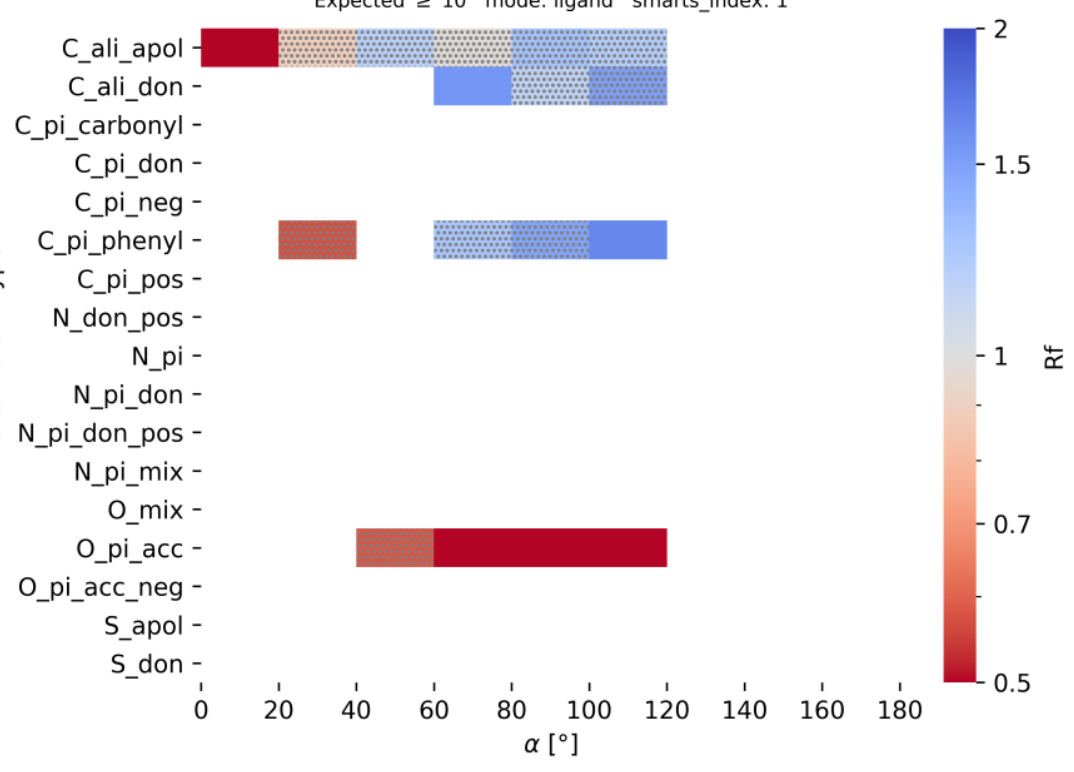


Figure S6: Heat maps for nitrile nitrogen

[C]\#[N]

Expected $\geq 10$ mode: protein smarts_index: 1

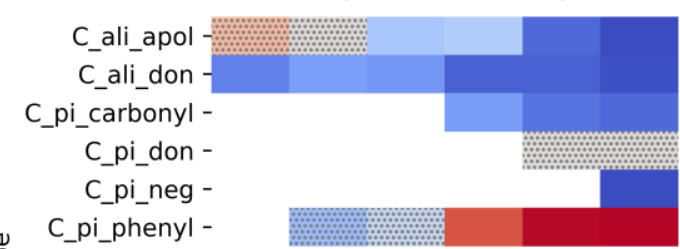

$\sum_{i}$ C_pi_pos

E N_don_pos -

帝 N- N_pi

高 N_pi_don -

은 N_pi_don_pos -

N_pi_mix -

O_pi_acc

O_pi_acc_neg -

S_apol -

S_don -

$\begin{array}{lllllllll}1 & 1 & 1 & 1 & 1 & 1 & 1 & 1 & 1 \\ 0 & 40 & 60 & 80 & 100 & 120 & 140 & 160 & 180\end{array}$

$\alpha\left[{ }^{\circ}\right]$

\section{$[\mathrm{C}] \#[\mathrm{~N}]$}

Expected $\geq 10$ mode: protein smarts index: 1

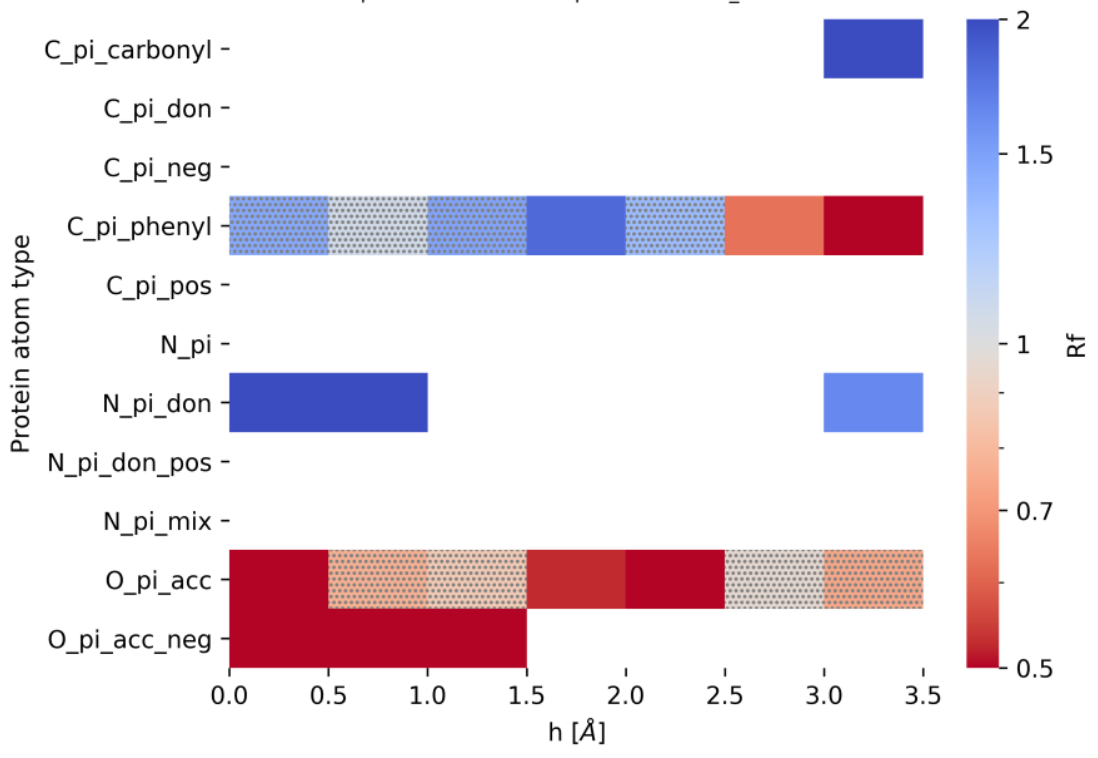

\section{[C]\#[N]}

Expected $\geq 10$ mode: ligand smarts_index: 1

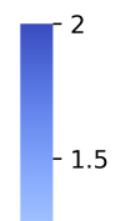

5

C_ali_apol -

C_ali_don -

C_pi_carbonyl -

C_pi_don -

$$
\text { C_pi_neg - }
$$

C C_pi_phenyl -

C_pi_pos -

E N_don_pos -

$1 \stackrel{4}{\dddot{\alpha}}$

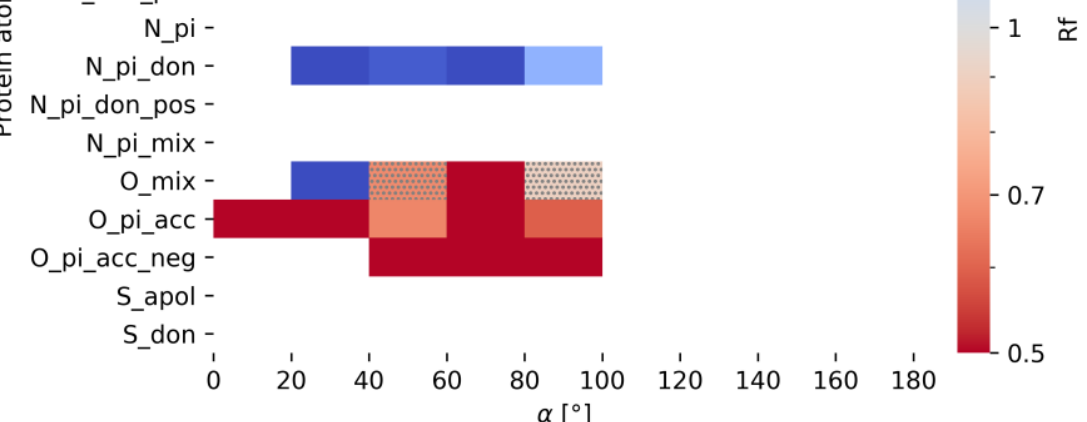


Figure S7: X-ray structure examples for nitrile...O_pi_acc and nitrile...O_pi_acc_neg contacts with highest observed $\mathrm{R}_{\mathrm{F}, \text { total }}$ values for these atom pairs

a)

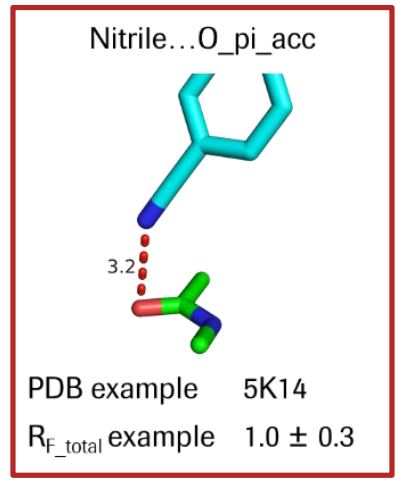

b)

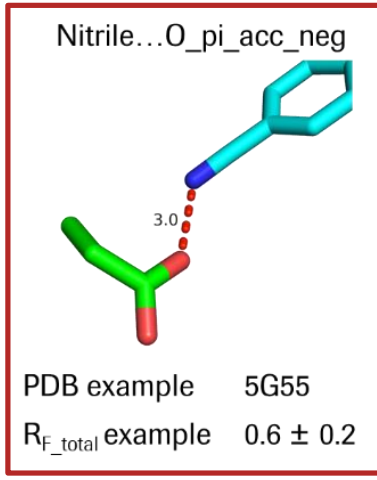


Figure S8: Heat maps for sulfonyl oxygen
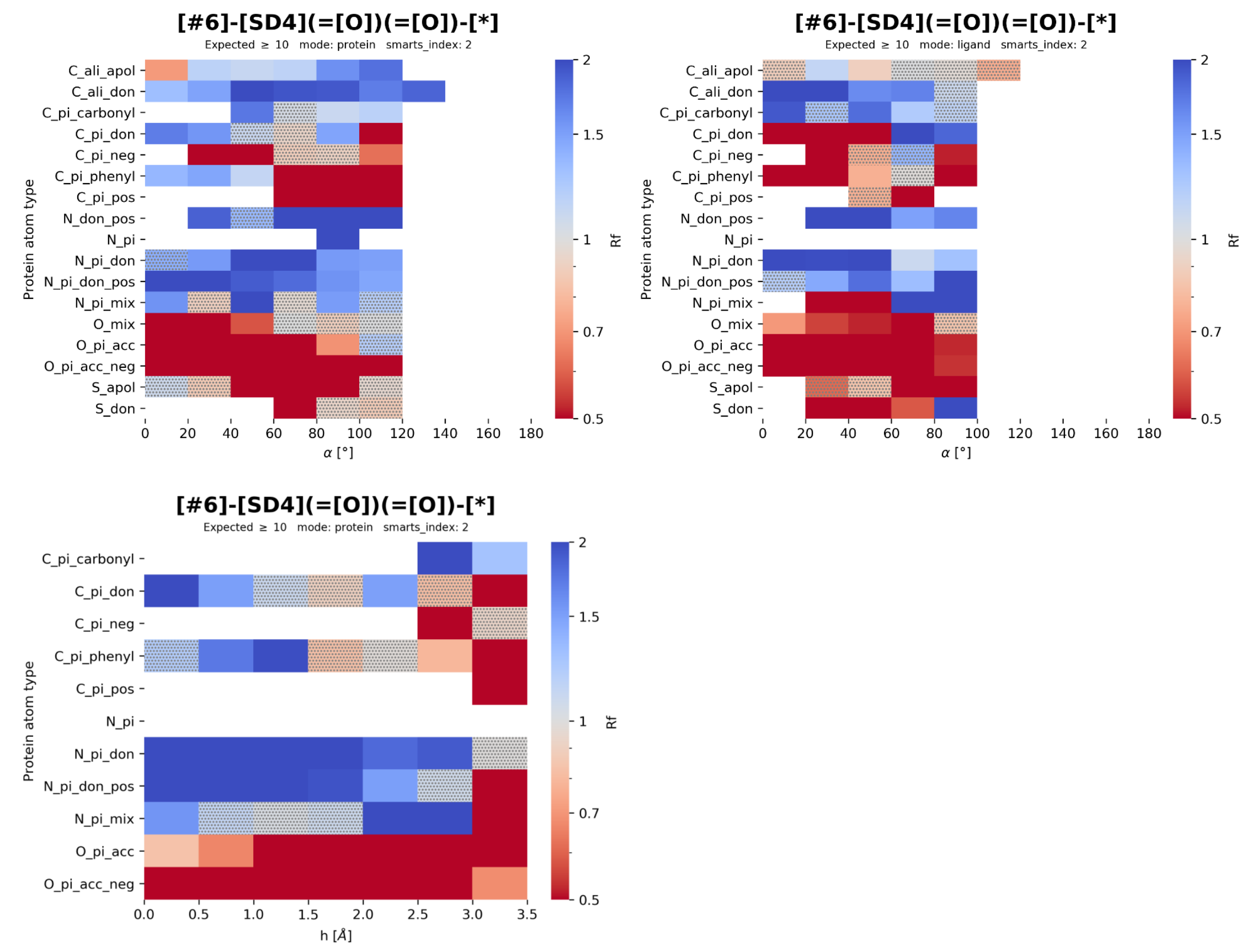
Figure S9: Heat maps for aromatic sulfur

[s]

Expected $\geq 10$ mode: protein smarts_index: 0

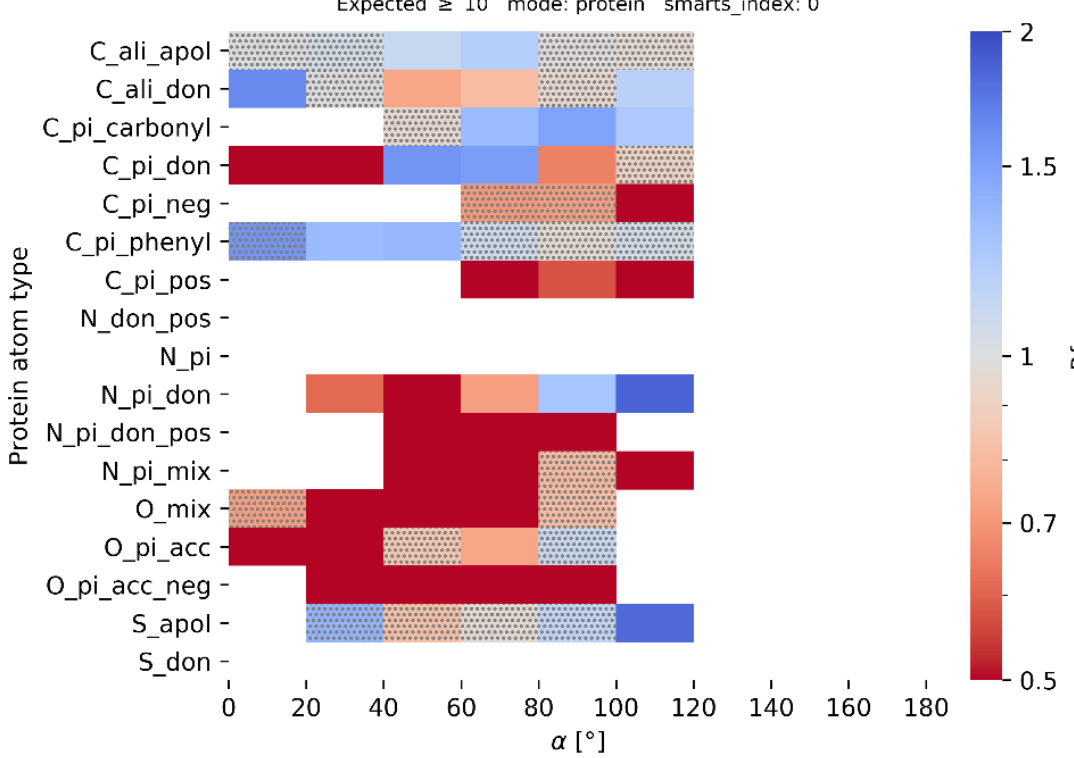

[s]

Expected $\geq 10$ mode: protein smarts_index: 0

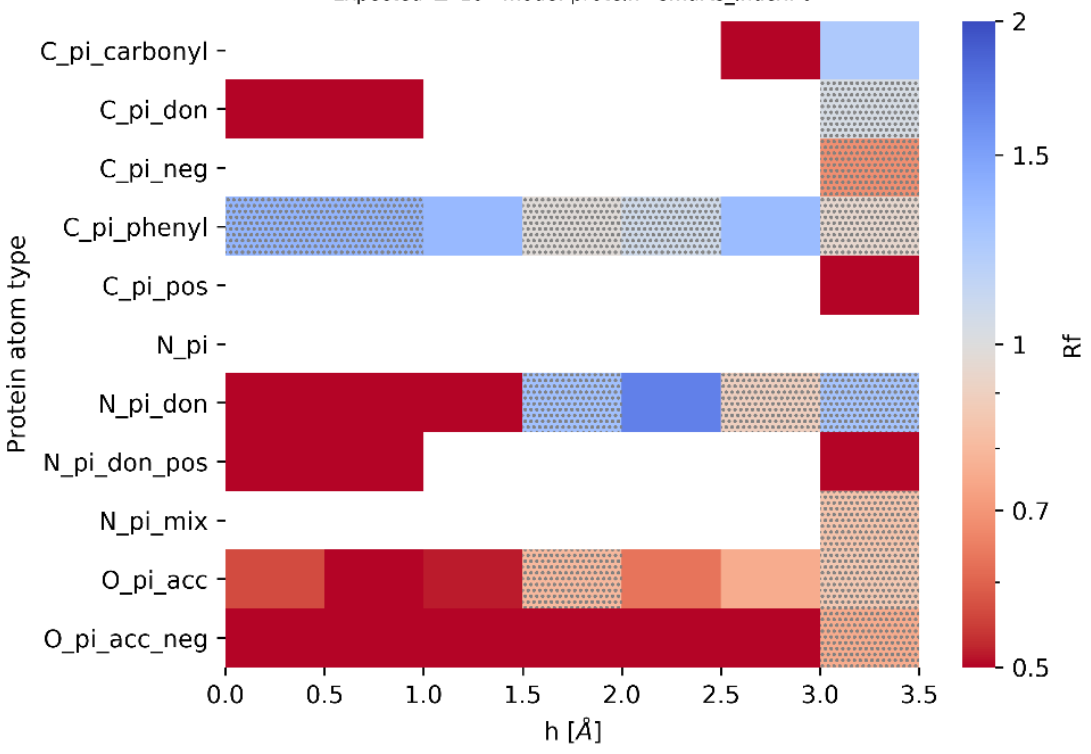

[s]

Expected $\geq 10$ mode: ligand smarts_index: 0

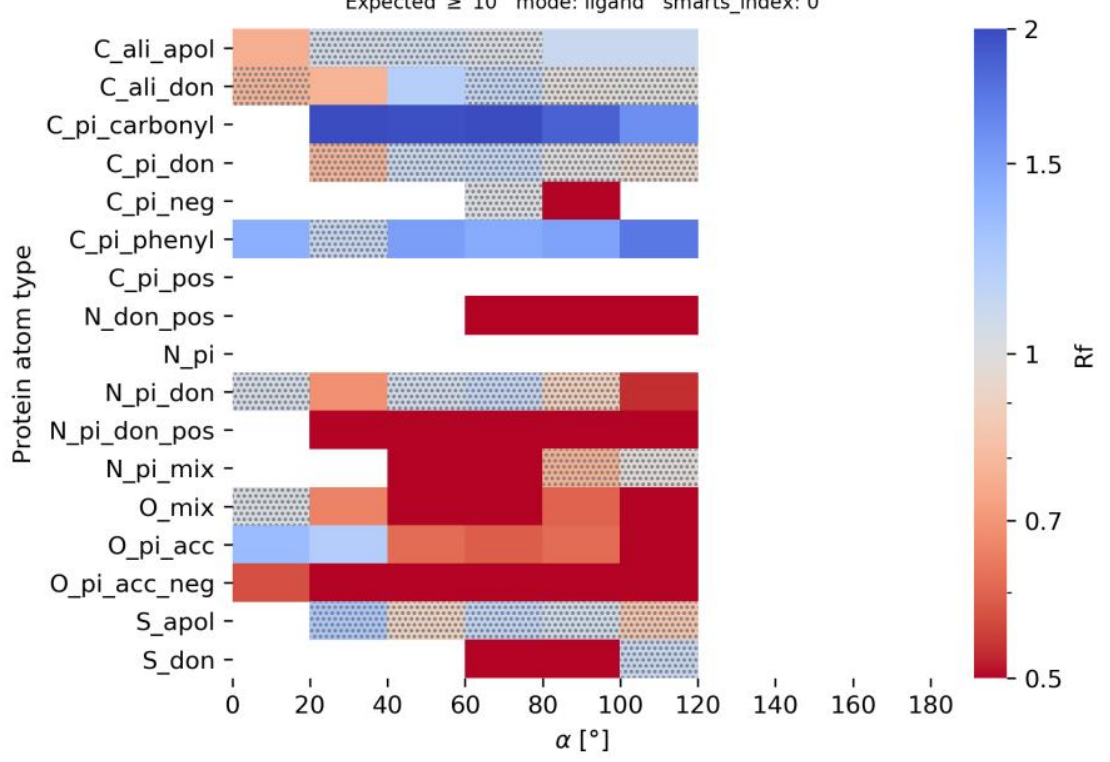

[s]

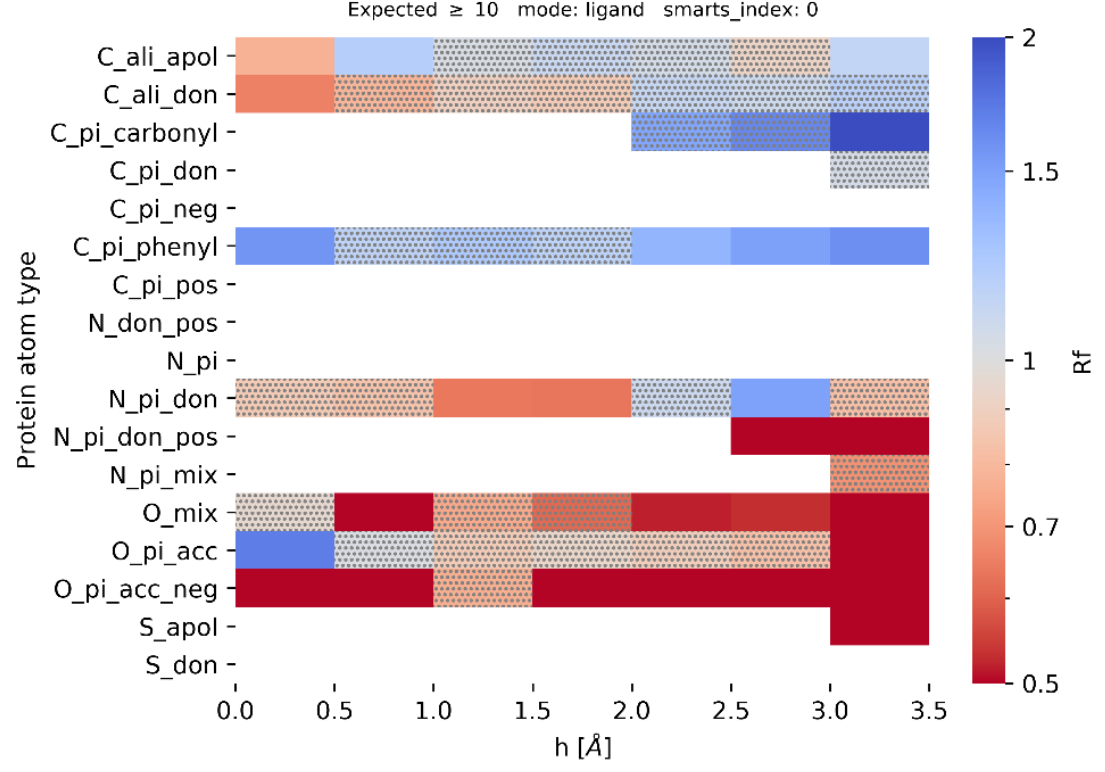


Figure S10: Heat maps for thiophene sulfur
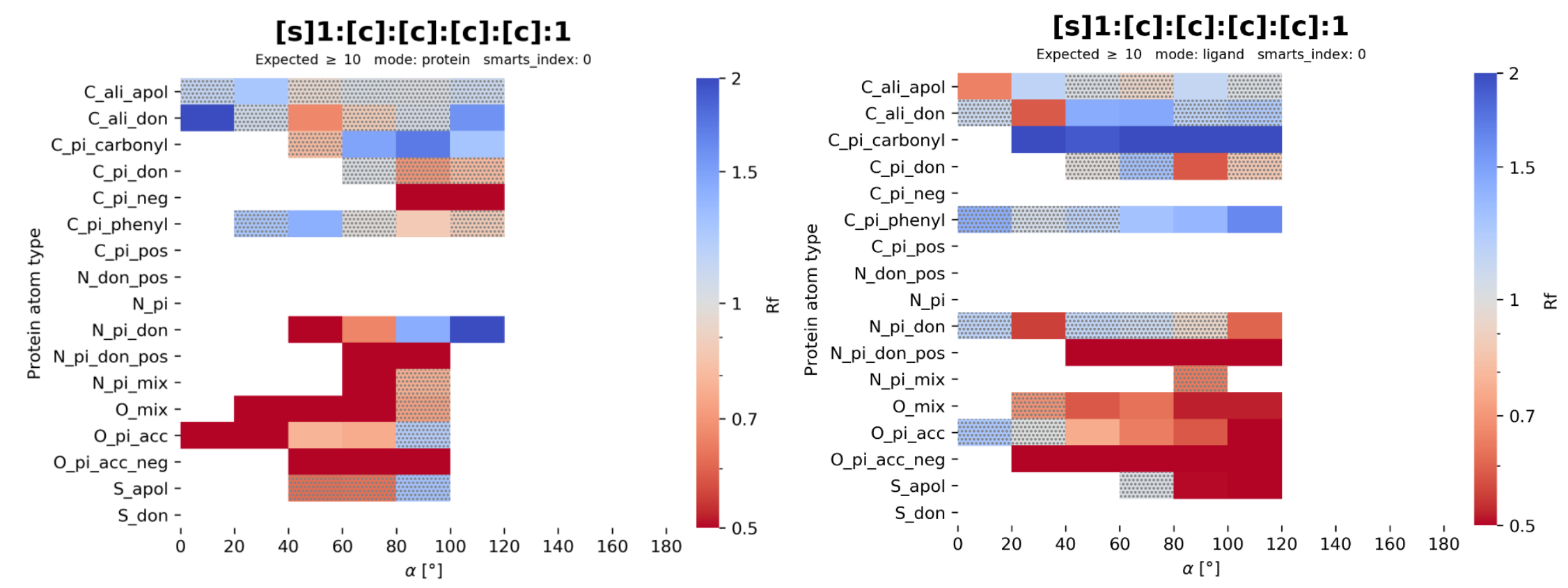

[s]1:[c]:[c]:[c]:[c]:1
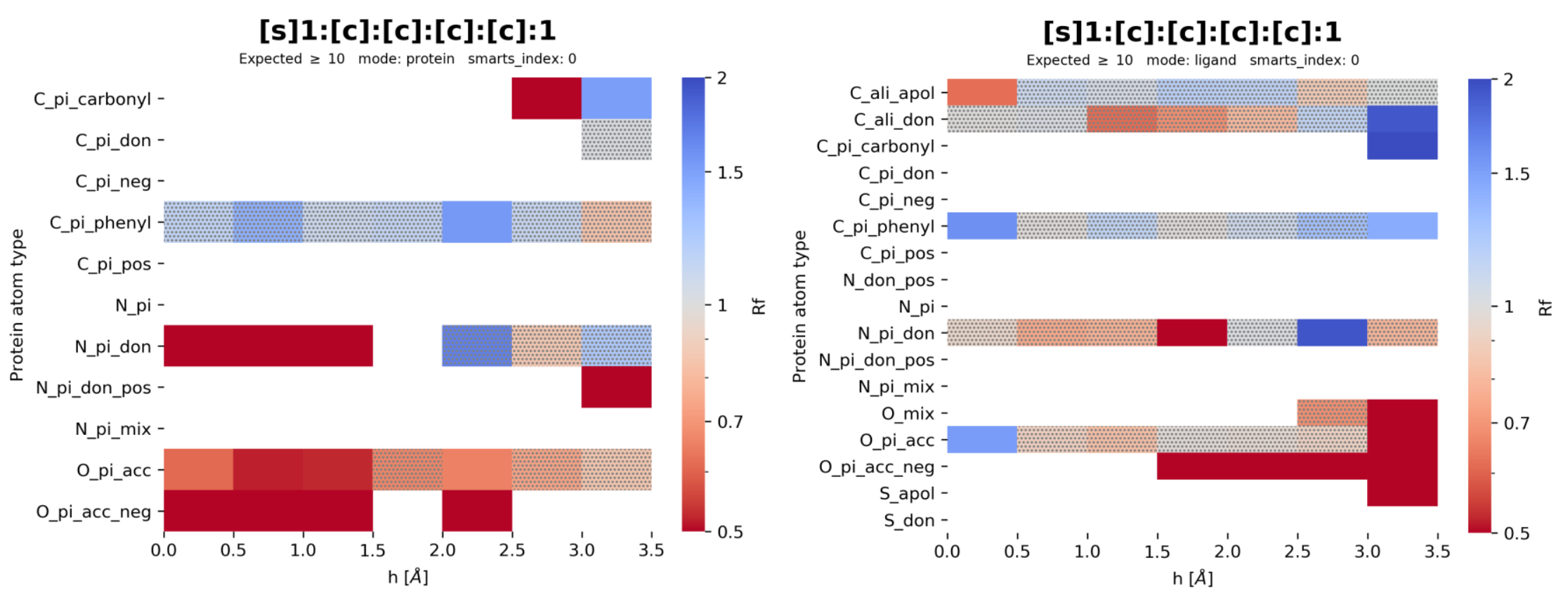
Figure S11: Heat maps for thiazole sulfur
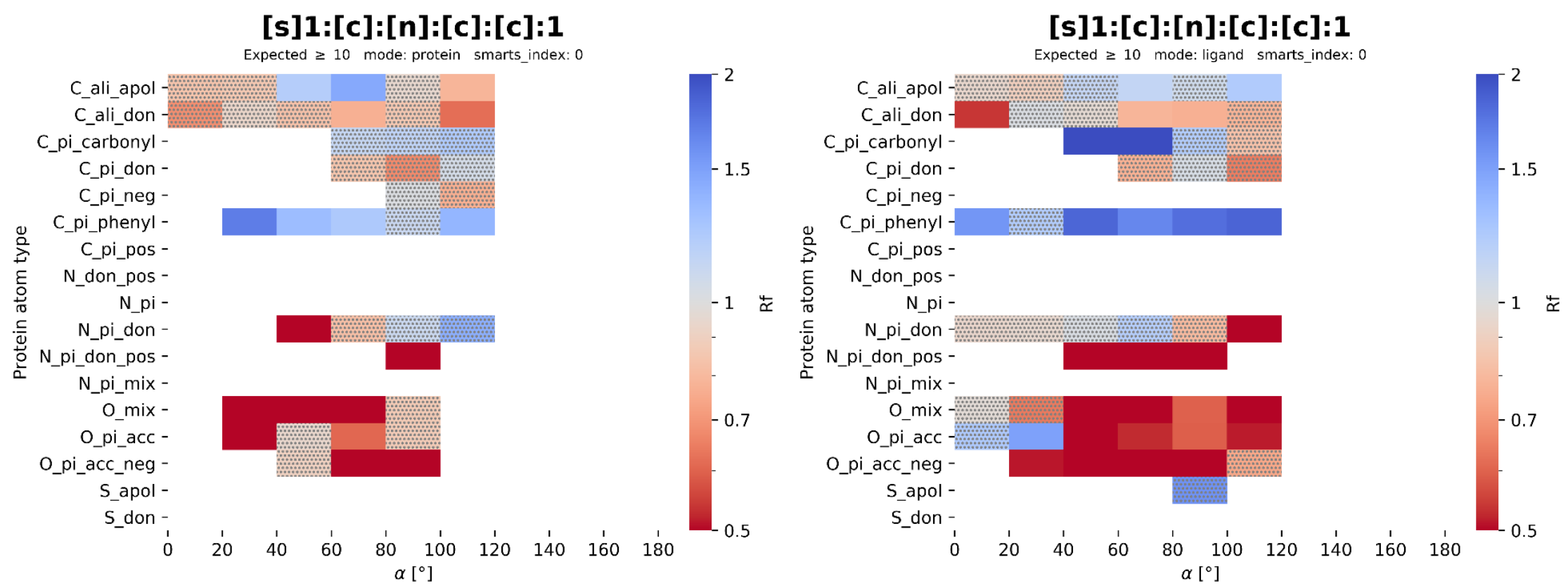

[s]1:[c]:[n]:[c]:[c]:1

Expected $\geq 10$ mode: protein smarts index: 0
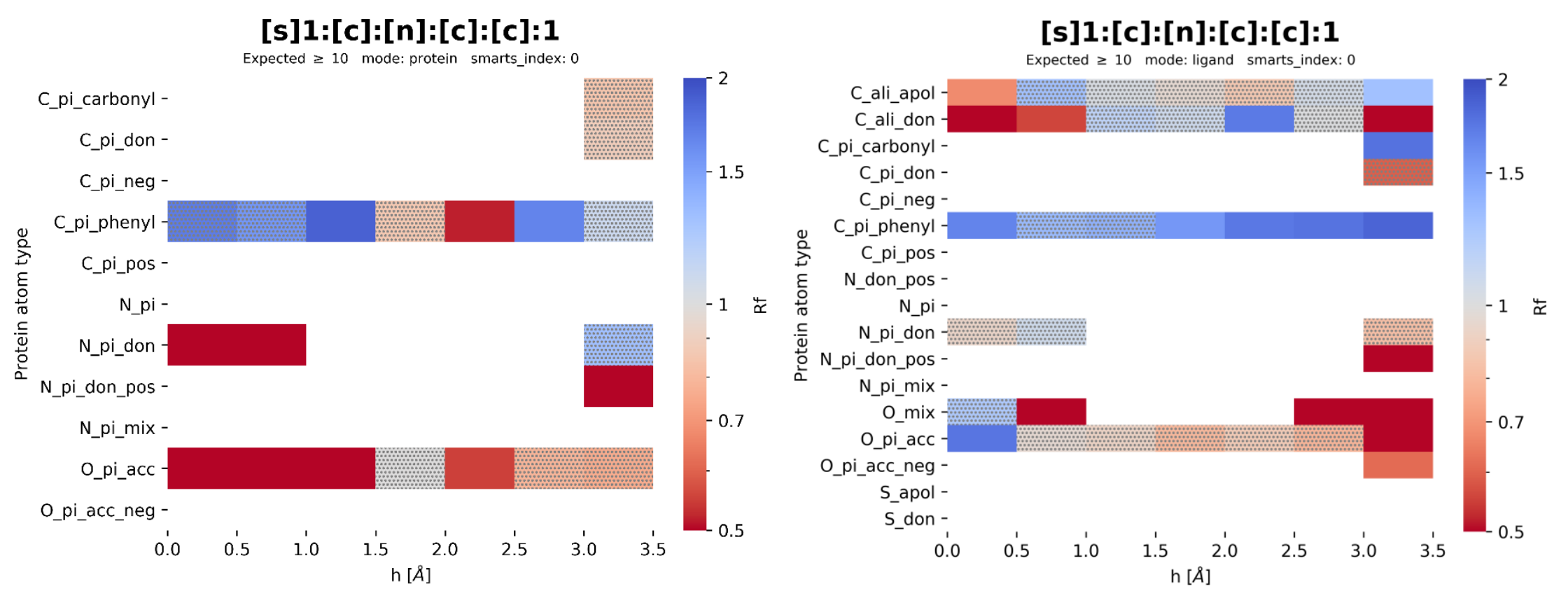
Protein preparation and crystallography.

To determine the structure of HCV polymerase NS5B bound to compound $\mathbf{1}$, the protein was expressed, purified and crystallized as described by Le Pogam et al. ${ }^{1}$ The structure was determined by molecular replacement using PDB 2 GIQ as a search model. Data reduction and refinement statistics are shown in Table S4. The structure factors and coordinates are deposited under PDB accession code 6W4G.

Table S4: Data collection and refinement statistics. Statistics for the highest-resolution shell are shown in parentheses.

\begin{tabular}{|l|l|}
\hline & 6W4G $($ HCVpol BK 1-570 with compound 1) \\
\hline Wavelength & 1.0000 \\
\hline Resolution range & $42.09-1.951(2.02-1.951)$ \\
\hline Space group & P 212121 \\
\hline Unit cell & 85.478104 .704126 .119909090 \\
\hline Unique reflections & $61466(1947)$ \\
\hline Completeness (\%) & $73.95(23.34)$ \\
\hline Wilson B-factor & 39.92 \\
\hline Reflections used in refinement & $61364(1905)$ \\
\hline Reflections used for R-free & $3058(105)$ \\
\hline R-work & $0.1903(0.3621)$ \\
\hline R-free & $0.2436(0.3355)$ \\
\hline Number of non-hydrogen atoms & 9189 \\
\hline macromolecules & 8721 \\
\hline ligands & 64 \\
\hline solvent & 404 \\
\hline Protein residues & 1104 \\
\hline RMS(bonds) & 0.020 \\
\hline RMS(angles) & 1.96 \\
\hline Ramachandran favored (\%) & 97.62 \\
\hline Ramachandran allowed (\%) & 2.29 \\
\hline Ramachandran outliers (\%) & 0.09 \\
\hline Rotamer outliers (\%) & 4.17 \\
\hline Clashscore & 4.78 \\
\hline Average B-factor & 47.87 \\
\hline macromolecules & 47.94 \\
\hline ligands & 51.30 \\
\hline solvent & 45.96 \\
\hline
\end{tabular}

(1) Le Pogam, S.; Kang, H.; Harris, S. F.; Leveque, V.; Giannetti, A. M.; Ali, S.; Jiang, W.-R.; Rajyaguru, S.; Tavares, G.; Oshiro, C.; Hendricks, T.; Klumpp, K.; Symons, J.; Browner, M. F.; Cammack, N.; Nájera, I. Selection and Characterization of Replicon Variants Dually Resistant to Thumb- and Palm-Binding Nonnucleoside Polymerase Inhibitors of the Hepatitis C Virus. J. Virol. 2006, 80 (12), 6146-6154. https://doi.org/10.1128/JVI.02628-05. 
Table S5: SMILES notation of hepatitis C virus polymerase compounds from Table 5.

\begin{tabular}{c|c} 
No. & SMILES \\
\hline 1 & $\mathrm{CC}(\mathrm{C})(\mathrm{C})[\mathrm{C} @ @ \mathrm{H}] 1 \mathrm{~N}(\mathrm{Cc} 2 \mathrm{ccc}(\mathrm{F}) \mathrm{c}(\mathrm{c} 2) \mathrm{C} \# \mathrm{~N}) \mathrm{C}(=\mathrm{O}) \mathrm{C}(=\mathrm{C} 1 \mathrm{O}) \mathrm{C} 3=\mathrm{NS}(=\mathrm{O})(=\mathrm{O}) \mathrm{c} 4 \mathrm{ccccc} 34$ \\
2 & $\mathrm{Cc} 1 \mathrm{cc}(\mathrm{CN} 2[\mathrm{C} @ \mathrm{H}](\mathrm{C}(=\mathrm{C}(\mathrm{C} 2=\mathrm{O}) \mathrm{C} 3=\mathrm{NS}(=\mathrm{O})(=\mathrm{O}) \mathrm{c} 4 \mathrm{ccccc} 34) \mathrm{O}) \mathrm{C}(\mathrm{C})(\mathrm{C}) \mathrm{C}) \mathrm{ccc} 1 \mathrm{~F}$ \\
3 & $\mathrm{CC}(\mathrm{C})(\mathrm{C})[\mathrm{C} @ @ \mathrm{H}] 1 \mathrm{~N}(\mathrm{Cc} 2 \mathrm{ccc}(\mathrm{F}) \mathrm{c}(\mathrm{Br}) \mathrm{c} 2) \mathrm{C}(=\mathrm{O}) \mathrm{C}(=\mathrm{C} 1 \mathrm{O}) \mathrm{C} 3=\mathrm{NS}(=\mathrm{O})(=\mathrm{O}) \mathrm{c} 4 \mathrm{ccccc} 34$ \\
4 & $\mathrm{CC}(\mathrm{C})(\mathrm{C})[\mathrm{C} @ @ \mathrm{H}] 1 \mathrm{~N}(\mathrm{Cc} 2 \mathrm{ccc}(\mathrm{F}) \mathrm{c}(\mathrm{Cl}) \mathrm{c} 2) \mathrm{C}(=\mathrm{O}) \mathrm{C}(=\mathrm{C} 1 \mathrm{O}) \mathrm{C} 3=\mathrm{NS}(=\mathrm{O})(=\mathrm{O}) \mathrm{c} 4 \mathrm{ccccc} 34$ \\
5 & $\mathrm{CC}(\mathrm{C})(\mathrm{C})[\mathrm{C} @ @ \mathrm{H}] 1 \mathrm{~N}(\mathrm{Cc} 2 \mathrm{ccc}(\mathrm{F}) \mathrm{c}(\mathrm{F}) \mathrm{c} 2) \mathrm{C}(=\mathrm{O}) \mathrm{C}(=\mathrm{C} 1 \mathrm{O}) \mathrm{C} 3=\mathrm{NS}(=\mathrm{O})(=\mathrm{O}) \mathrm{c} 4 \mathrm{ccccc} 34$ \\
6 & $\mathrm{COc} 1 \mathrm{cc}(\mathrm{CN} 2[\mathrm{C} @ \mathrm{H}](\mathrm{C}(=\mathrm{C}(\mathrm{C} 2=\mathrm{O}) \mathrm{C} 3=\mathrm{NS}(=\mathrm{O})(=\mathrm{O}) \mathrm{c} 4 \mathrm{ccccc} 34) \mathrm{O}) \mathrm{C}(\mathrm{C})(\mathrm{C}) \mathrm{C}) \mathrm{ccc} 1 \mathrm{~F}$ \\
7 & $\mathrm{CCc} 1 \mathrm{cc}(\mathrm{CN} 2[\mathrm{C} @ \mathrm{H}](\mathrm{C}(=\mathrm{C}(\mathrm{C} 2=\mathrm{O}) \mathrm{C} 3=\mathrm{NS}(=\mathrm{O})(=\mathrm{O}) \mathrm{c} 4 \mathrm{ccccc} 34) \mathrm{O}) \mathrm{C}(\mathrm{C})(\mathrm{C}) \mathrm{C}) \mathrm{ccc} 1 \mathrm{~F}$ \\
8 & $\mathrm{CC}(\mathrm{C})(\mathrm{C})[\mathrm{C} @ @ \mathrm{H}] 1 \mathrm{~N}(\mathrm{Cc} 2 \mathrm{ccc}(\mathrm{F}) \mathrm{c}(\mathrm{c} 2) \mathrm{C} \# \mathrm{~N}) \mathrm{C}(=\mathrm{O}) \mathrm{C}(=\mathrm{C} 1 \mathrm{O}) \mathrm{C} 3=\mathrm{NS}(=\mathrm{O})(=\mathrm{O}) \mathrm{c} 4 \mathrm{ccccc} 34$
\end{tabular}


Figure S12: Example of a non-competitive interactions of fluorine with C_pi_neg. Despite the low RF value, replacing the fluorine by a hydrogen only slightly increases binding affinity. The label next to the dashed line indicates the atom centre distance in $\AA$. RF ranges for non-competitive interactions between these atom types are (Figure S3): protein contact angle: $80^{\circ}$ $100^{\circ}$, protein $\pi$-distance: -, ligand contact angle: $60^{\circ}-80^{\circ}$.

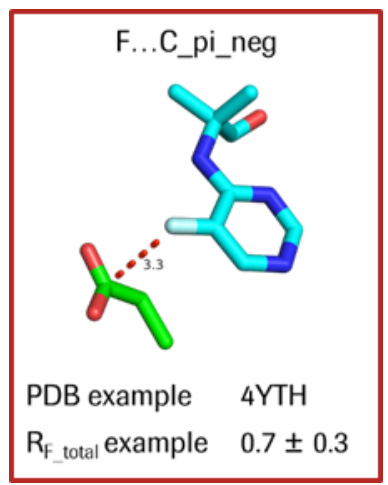


Figure S13: Heat map for chlorine bound to aromatic carbon, including refined protein atom type definitions and water (ligand perspective, angle constrained).

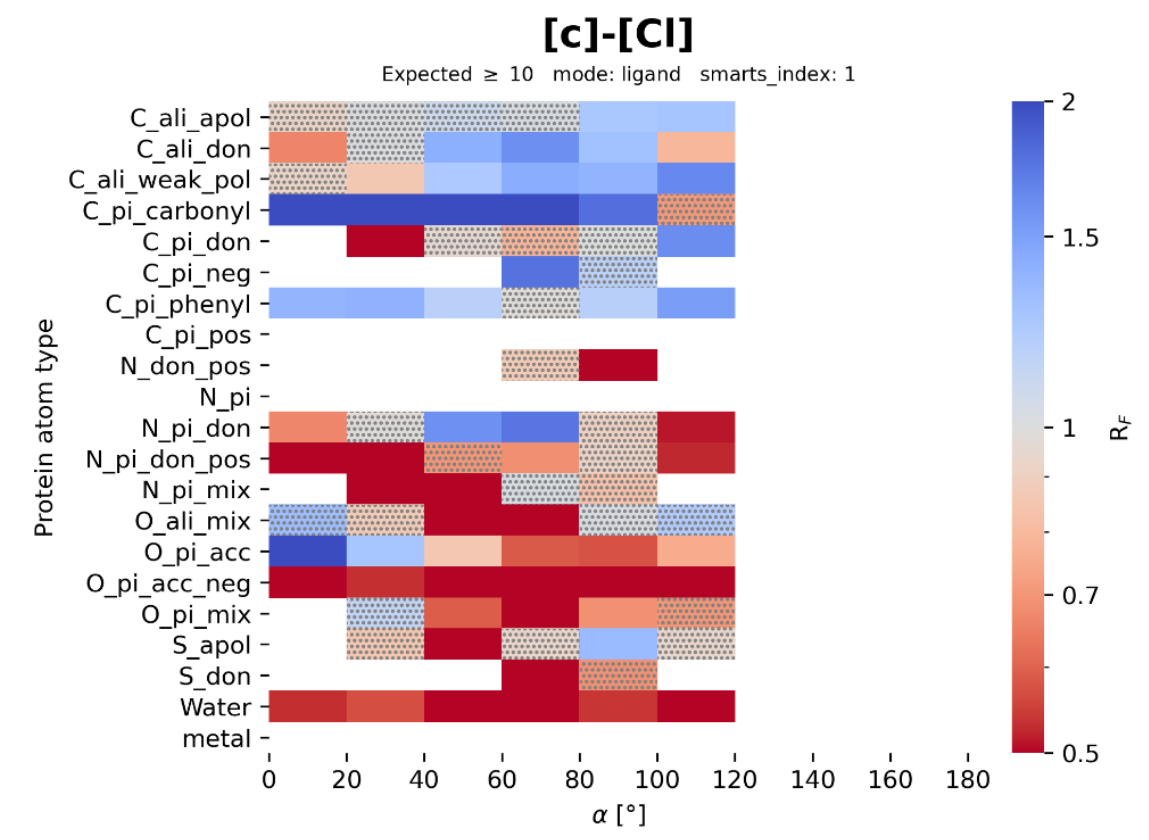


Figure S14: Deviation from the true $\mathrm{R}_{\mathrm{F}}$ value for different "expected" thresholds. The value "Bin" gives the range of expected values, and "Samples" the number of pseudo $R_{F}$ values, whose expected value falls in the corresponding bin. For example: $\operatorname{Bin}(5,6)$, Samples 85 means that for 85 pseudo $R_{F}$ values, the expected value was between five and six.
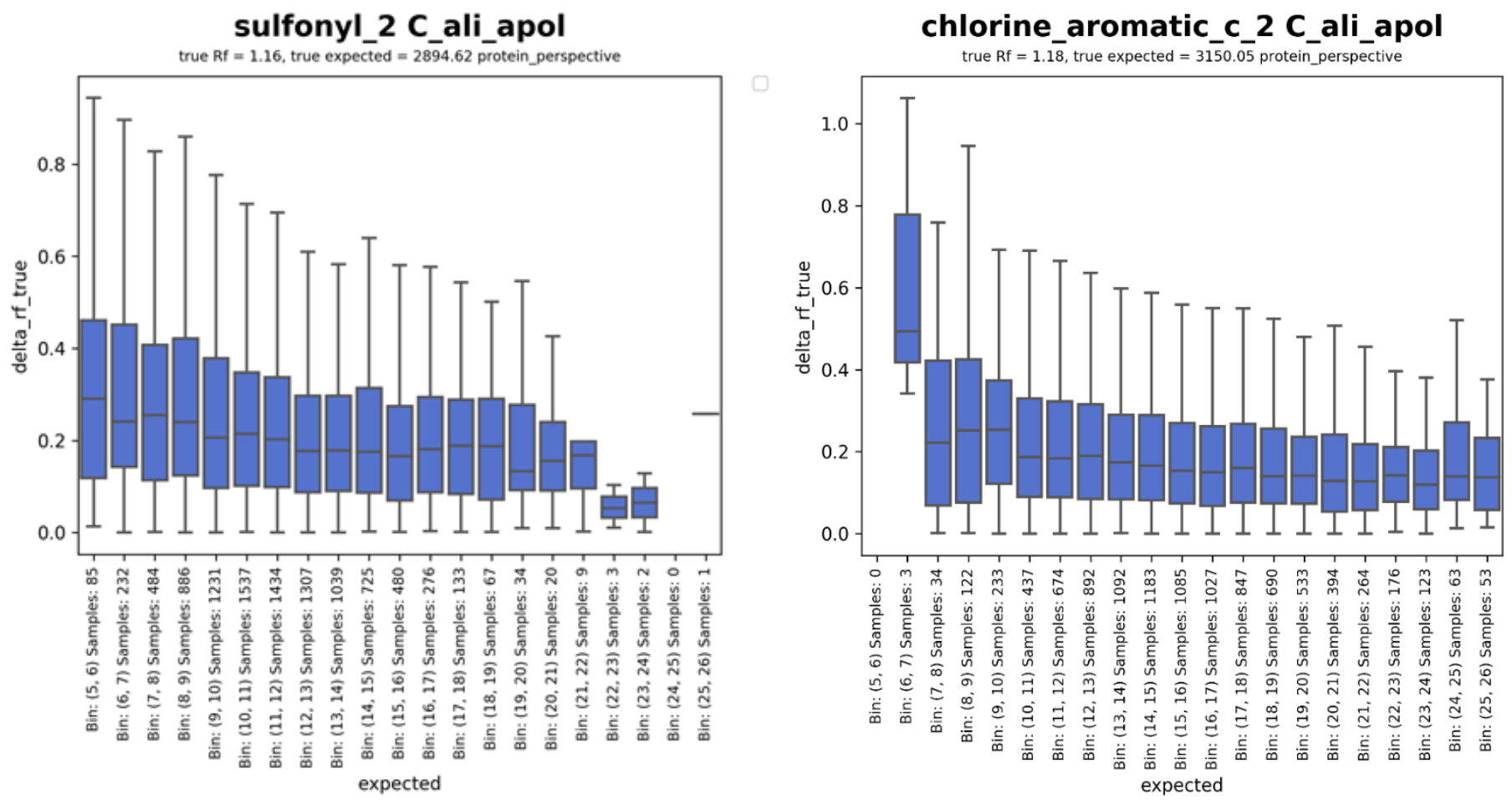
Figure S15: Effect of number of bootstrapping cycles on the size of the confidence interval for different "expected" values.

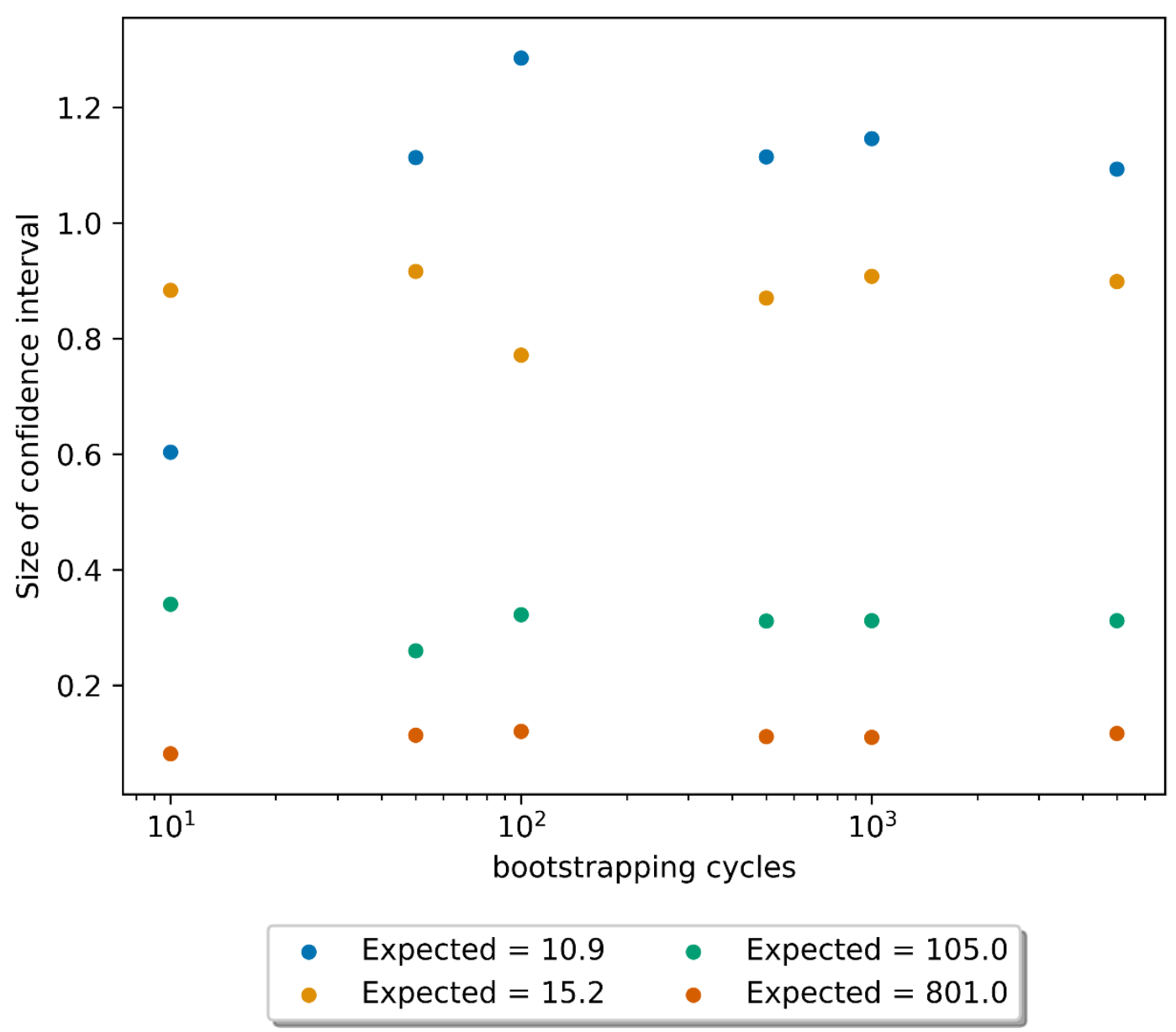

